\title{
Conducta expectante en el queratoacantoma solitario
}

\section{Expectant management of solitary keratoacanthoma}

Lola Kuperman Wilder ${ }^{1}$, Romina Foenquinos ${ }^{2}$, Ana Clara Acosta ${ }^{3}$ y César Chiappe ${ }^{4}$

\section{RESUMEN}

El queratoacantoma solitario es un tumor queratinocítico localizado en zonas fotoexpuestas que se caracteriza por tener tres fases evolutivas: una primera de crecimiento rápido, una de estabilidad y una final de involución espontánea. Esta última no se observa con tanta frecuencia porque su diagnóstico diferencial, el carcinoma espinocelular, obliga a que la terapia de elección sea la escisión quirúrgica. La decisión de mantener una conducta expectante debe tomarse junto con el paciente, quien debe conocer los riesgos que esta implica. Presentamos los casos de dos pacientes que rechazaron la opción quirúrgica y tuvieron una evolución favorable con una estricta supervisión clínica.

Palabras clave: queratoacantoma, carcinoma espinocelular.

Dermatol. Argent. 2020, 26 (3): 101-104

\section{ABSTRACT}

Keratoacanthoma is an epithelial proliferative lesion that develops on sun-exposed skin. It is characterized for having three phases, initial rapid growth is followed by a period of stability and finally, a spontaneous regression. The last phase is rarely seen because the gold standard therapy is surgical removal due to the impossibility to differentiate it from squamous cell carcinoma. The "watch and wait policy" should be agreed with the patient and we must inform the possibility of its aggressive behavior. We present two cases that chose to defer therapy and had a spontaneous resolution with regular close follow-ups.

Key words: keratoacanthoma, squamous cell carcinoma.

Dermatol. Argent. 2020, 26 (3): 101-104

\footnotetext{
1 Médica Residente de Primer año

2 Médica Dermatóloga, Sector Oncología

3 Médica Dermatóloga. Médica de Planta, Sector Oncología

4 Médico Patólogo

División Dermatología, Hospital General de Agudos J. M. Ramos Mejía, Ciudad Autónoma de Buenos Aires, Argentina
}

Contacto del autor: Lola Kuperman Wilder E-mail: lolakuperman@gmail.com Fecha de trabajo recibido: $3 / 6 / 2020$ Fecha de trabajo aceptado: 25/9/2020 Conflicto de interés: los autores declaran que no existen conflicto de interés.

\section{INTRODUCCIÓN}

El queratoacantoma (QA) solitario es un tumor controvertido de origen epidérmico. Se caracteriza por un crecimiento rápido y exofítico, seguido por una fase de estabilidad y, por último, suele presentar regresión espontánea. El mecanismo de involución no está definido en su totalidad. Según una de las hipótesis que se han planteado, la presencia de un denso infiltrado de linfocitos $\mathrm{T}$ en la base del tumor podría tener un papel en su regresión. Otra teoría se apoya en su origen en la vaina radicular externa del folículo piloso, con una evolución que remeda las fases del ciclo del pelo ${ }^{1}$.

Si bien la regresión espontánea sería la evolución natural del QA, no se recomienda esperar a que esto suceda, ya que su principal diagnóstico diferencial es el carcinoma espinocelular (CEC). Por sus similitudes y la ausencia de criterios clinicopatológicos estrictos para distinguirlos, la indicación terapéutica de primera elección es la escisión quirúrgica. Sin embargo, hay otras opciones para los pacientes que de- 
ciden rechazar la cirugía o postergarla. Presentamos los casos de 2 pacientes que se negaron a realizar el tratamiento quirúrgico sugerido y que tuvieron una evolución favorable con la conducta expectante.

\section{CASOS CLÍNICOS}

\section{Caso clínico 1}

Una mujer de 74 años, con antecedentes de hipertensión arterial, hipercolesterolemia y múltiples carcinomas espinocelulares y basocelulares en zonas fotoexpuestas, consultó por la presencia de una lesión en la nariz, de rápido crecimiento, de 2 meses de evolución.

En el examen físico se observaba un tumor en la ladera nasal izquierda, de $9 \mathrm{~mm}$ de diámetro, con borde sobreelevado y centro crateriforme, que asentaba sobre la cicatriz quirúrgica de un carcinoma basocelular resecado con márgenes libres 2 años antes (Foto 1). Como diagnósticos presuntivos se plantearon $\mathrm{QA}, \mathrm{CEC}$ y recidiva del carcinoma basocelular.

Se realizó una biopsia incisional en cuña, cuya histología informó: "Presencia de dos lóbulos a nivel de la dermis a expensas de queratinocitos de aspecto vítreo asociados a denso infiltrado inflamatorio mononuclear y polimorfonuclear y aisladas imágenes de coilocitosis (probable acción citopática por el virus del papiloma humano)". Se arribó al diagnóstico clinicohistológico de QA y se indicó la extirpación quirúrgica completa, pero la paciente se negó. Debido a la reducción del tamaño tumoral luego de la biopsia, se decidió, junto con la paciente, realizar controles evolutivos mensuales. Al mes, la lesión presentaba una franca disminución del tamaño y a los 2 meses, había desaparecido (Foto 2). La paciente continuó el seguimiento durante 6 años y no presentó recidivas.

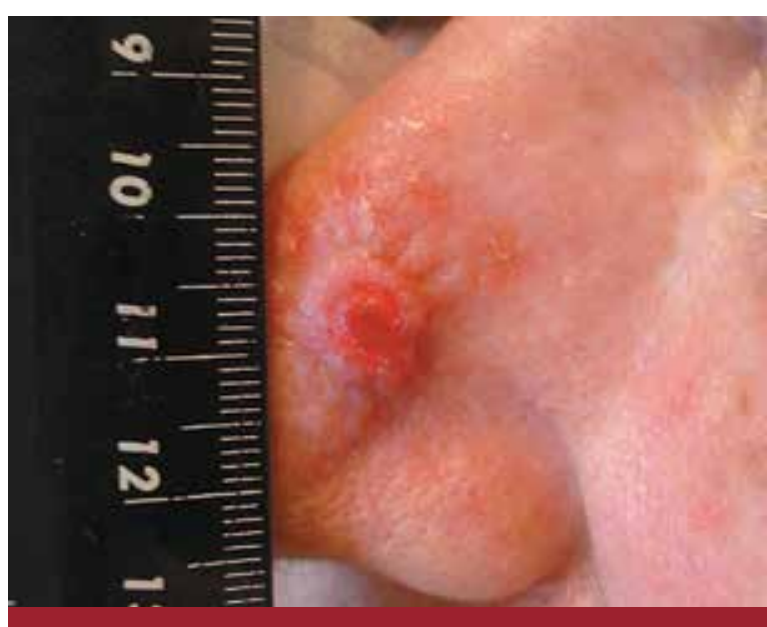

F0T0 1: Lesión de aspecto crateriforme, de $9 \mathrm{~mm}$ de diámetro, localizada en la ladera nasal izquierda, de 2 meses de evolución.

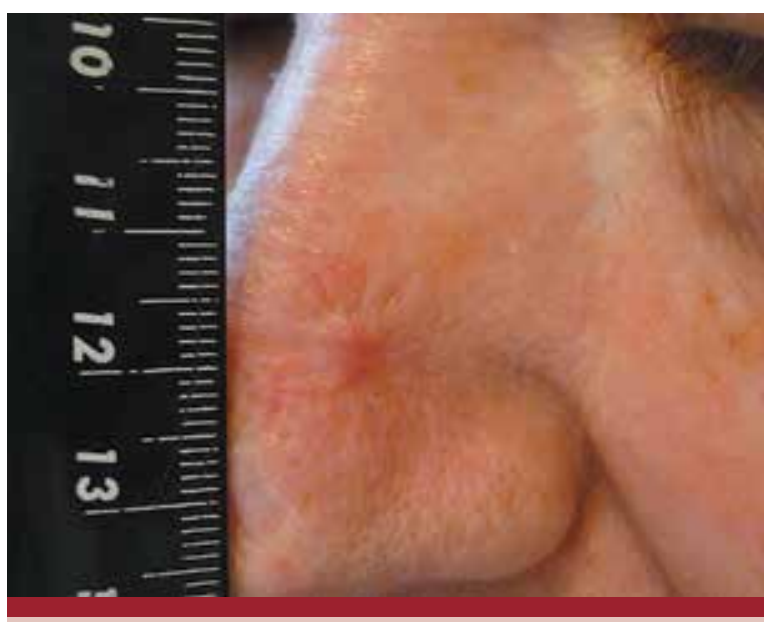

FOTO 2: Pequeña cicatriz a los 2 meses de la lesión inicial.

\section{Caso clínico 2}

Un paciente de 82 años, con antecedentes de enfermedad vascular periférica, hipertensión arterial y dislipidemia, consultó por una lesión localizada en el antebrazo derecho, de 45 días de evolución.

En el examen físico se observaba una lesión tumoral de $1,5 \mathrm{~cm}$ de diámetro, con un centro costroso y bordes sobreelevados (Foto 3), acompañada de un intenso fotodaño. Como diagnósticos presuntivos se plantearon QA y CEC.

Se realizó una biopsia incisional en cuña y el estudio histopatológico informó: "Proliferación epitelial escamosa de configuración exoendofítica con marcada hiperqueratosis, constituida por lóbulos invaginados de células con citoplasma amplio, pálido, eosinófilo, de aspecto vítreo y tendencia a la queratinización central, asociado a moderado infiltrado inflamatorio mononuclear en la dermis subyacente" (Fotos 4 y 5). Por lo tanto, se estableció el diagnóstico clinicohistológico de QA.

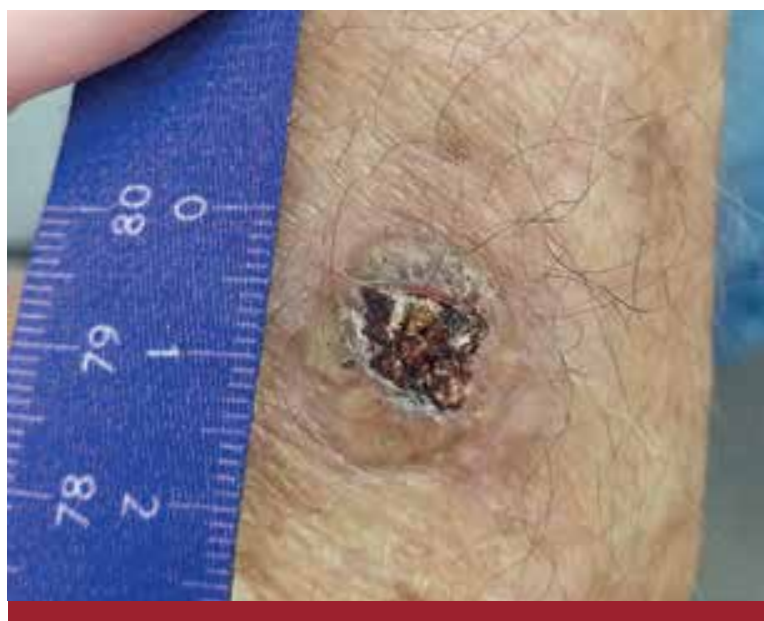

F0T0 3: Lesión de 1,5 $\mathrm{cm}$ de diámetro, con centro costroso y bordes sobreelevados, en el antebrazo derecho, de 45 días de evolución. 


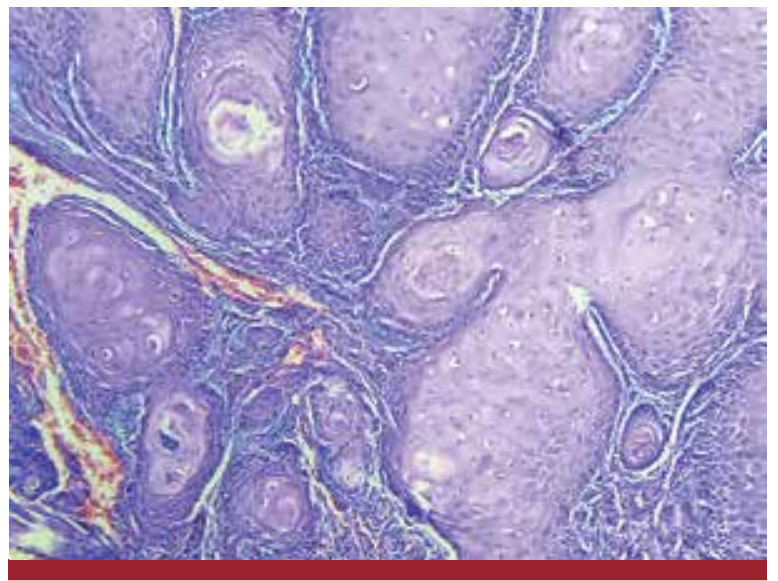

FOTO 4: Lóbulos constituidos por queratinocitos de citoplasma amplio, pálido, eosinófilo. Algunos de ellos exhiben queratinización central (HyE, 100X).

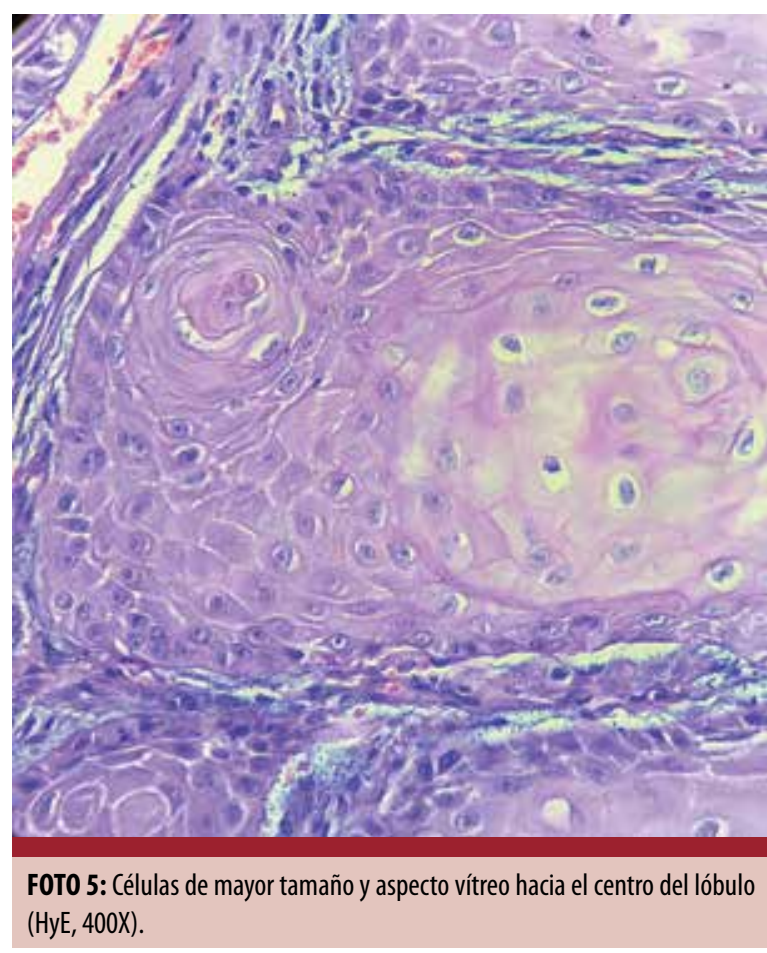

Se indicó la resección quirúrgica completa, pero el paciente se negó a ese tratamiento. Se realizó el control evolutivo y, a los 2 meses del diagnóstico, se constató la desaparición de la lesión y, en su lugar, se apreciaba solo una cicatriz atrófica hipopigmentada (Foto 6). El paciente continuó el seguimiento por un año, sin presentar recurrencias.

\section{COMENTARIOS}

El QA solitario es un tumor cutáneo queratinocítico frecuente, que suele presentarse como una lesión crateriforme de 1 a $2 \mathrm{~cm}$, con un centro hiperqueratósico. Su característica distintiva es su curso clínico con tres fases. En la primera crece con rapidez, en la segunda se mantiene estable y en la última involuciona de manera espontánea. Su

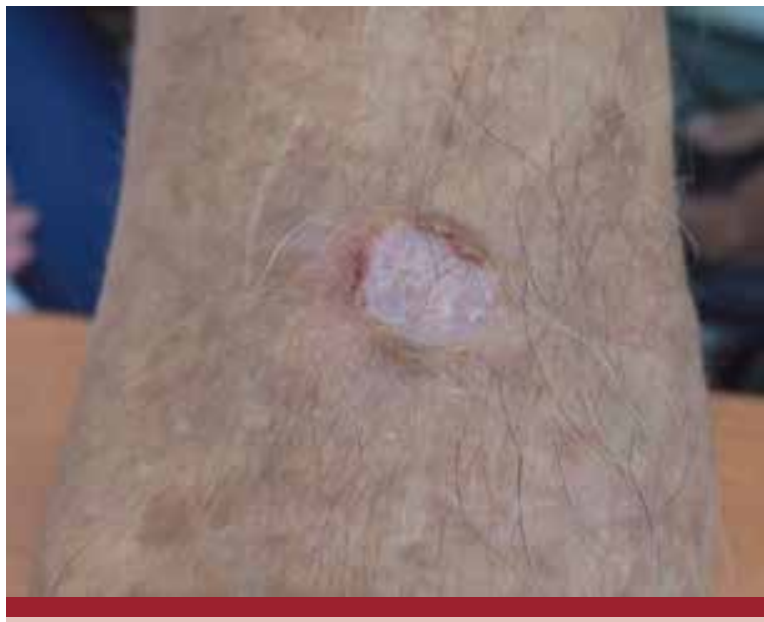

FOTO 6: Cicatriz atrófica hipopigmentada, 2 meses después de la lesión inicial.

categorización es problemática, ya que las similitudes con el CEC obligan a debatir si se debe clasificar o no como maligno $^{2}$. En los casos comentados, al no realizar el tratamiento quirúrgico propuesto, se observó la evolución "natural" de ambas lesiones con sus tres fases clínicas características.

En 1889, sir John Hutchinson describió por primera vez el QA como "úlceras crateriformes en la cara"citado por 3. Su forma clásica suele observarse en pacientes de alrededor de 50 años, con leve predominio en los hombres sobre las mujeres. Se describieron diversos factores de riesgo asociados: la exposición natural y artificial a la luz ultravioleta (el más importante), la asociación con el virus del papiloma humano (HPV), la inmunosupresión, el uso de inhibidores BRAF y el traumatismo (p. ej., los casos publicados sobre cicatrices quirúrgicas y tatuajes) $)^{1,2,4-7}$. Resaltamos en el primer caso presentado el desarrollo de la lesión sobre una cicatriz quirúrgica previa y la presencia de coilocitos vinculables al HPV.

El QA se puede presentar de forma solitaria o múltiple, esporádico o asociado a un síndrome genético o a enfermedades inflamatorias. A diferencia del CEC, deriva de la vaina radicular externa del folículo piloso, por lo que su naturaleza trifásica imita el ciclo del pelo. La variante solitaria, la más frecuente, se caracteriza por un rápido crecimiento en 4 a 5 semanas y suele ubicarse en zonas fotoexpuestas (cara y brazos). Una vez desarrollada, se puede observar una lesión nodular de $1 \mathrm{a} 2 \mathrm{~cm}$, rosada y cupuliforme, con un tapón central de queratina. Después de 4 a 9 meses, suele involucionar espontáneamente y puede dejar una cicatriz ${ }^{1,2,8}$.

El diagnóstico se basa en tres pilares: presentación clínica típica, curso trifásico y una biopsia adecuada ${ }^{2}$. Esta última debe ser incisional en cuña y debe incluir el centro queratósico, la zona sobreelevada y piel sana, para así poder observar la arquitectura macroscópica y microscópica que lo diferencian del CEC. 
Los hallazgos más frecuentes en la histopatología son la simetría y la clara demarcación entre el tumor y el estroma. Se destaca la ausencia de atipia, de desorden estructural y de desmoplasia estromal. Además, en su arquitectura característica, la epidermis se extiende a lo largo del tumor y en forma de labio alrededor de un cráter central con contenido de queratina.

Estos hallazgos son más característicos del QA, pero no excluyen por completo al CEC 2 . En un estudio sobre tumores crateriformes con rápido crecimiento, de los 19 compatibles histológicamente con el QA, los 6 que mostraron evidencia clínica de regresión al mes carecían de mitosis atípicas, mostraban fibrosis dérmica y tenían abscesos neutrofílicos y eosinofílicos intraepidérmicos ${ }^{9}$. Por eso, la mayoría de las biopsias en estas lesiones son descriptivas, como en los casos analizados.

Si bien la inmunohistoquímica puede ayudar a la diferenciación entre QA y CEC, todavía no se realiza con fines diagnósticos. Ambos tienen expresión de marcadores de neovascularización (CD105 y CD34), de p53 y de Ki67. La diferencia más importante es que Ki67 tiene menor expresión en QA y, además, varía según la etapa evolutiva (mayor en el crecimiento y menor en la involución) ${ }^{10}$.

Por la imposibilidad de distinguir con certeza el CEC del QA, el tratamiento de elección del QA solitario es la extirpación quirúrgica con márgenes de $4 \mathrm{~mm}$ que deben extenderse, idealmente, hasta el tejido adiposo. Otras opciones terapéuticas son: crioterapia, electrocoagulación y curetaje, agentes tópicos (imiquimod, 5-fluorouracilo, corticosteroides), quimioterápicos intralesionales (interferón, 5-fluorouracilo, metotrexato y bleomicina), radiación (aunque requiere la misma dosis que un CEC). Cuando está disponible, la cirugía de Mohs es la opción terapéutica ideal para áreas estéticamente sensibles, así como en los QA gigantes (mayores de $2 \mathrm{~cm})^{2,10}$.

\section{BIBLIOGRAFÍA}

1. Ko CJ. Keratoacanthoma: facts and controversies. Clin Dermatol 2010;28:254-261.

2. Kwiek B, Schwartz RA. Keratoacanthoma (KA): an update and review. J Am Acad Dermatol 2016;74:1220-1233.

3. Kitkhan N. Tumors and cysts of the epidermis. En: Elder DE, Elenitsas R, Johnson BL, Murphy GF, et ál. Levers's histopathology of the skin. Lippincott Williams \&Wilkins, Philadelphia, 2009:835-838.

4. A Le Bert Z, Soto D, Vial V, Bentjerodt R, et ál. Queratoacantoma subungueal. A propósito de un caso [en línea]. Rev Argent Dermatol 2015; 96. Disponible en: http://rad-online.org. ar/2016/01/01/queratoacantoma-subungueal-a-proposito-deun-caso/ [Consulta: abril 2020].

5. Griffiths RW. Keratoacanthoma observed. $\mathrm{Br} J$ Plast Surg 2004;57:485-501.

6. Pattee SF, Silvis NG. Keratoacanthoma developing in sites of previous trauma: a report of two cases and review of the literature. J Am Acad Dermatol 2003;48:S35-S38.

7. Gençler B, Gönül M. Cutaneous side effects of braf inhibitors in advanced melanoma: review of the literature. Dermatol Res Pract 2016;2016:5361569.
Aunque no se ha establecido un período seguro de control clínico, se ha sugerido que aquellas lesiones que no involucionan al año deben tratarse siempre de forma quirúrgica ${ }^{11}$. Otros estudios indican mantener una conducta expectante por un mes y revaluar ${ }^{12}$. En 14 pacientes observados por Griffiths et ál., el tiempo promedio de autoinvolución fue de 27 semanas y no hubo recurrencias a los 3 años del diagnóstico, con cicatrices estéticamente aceptables ${ }^{5}$. Browne et ál. propusieron sumar un control iconográfico al seguimiento clínico estricto cada 2 semanas por un mismo profesional avezado en el tema ${ }^{8}$. En los casos presentados, se realizaron controles clínicos e iconográficos mensuales y a largo plazo, sin recurrencias.

El estudio sobre el mecanismo de involución del QA aún es insuficiente. Como dijimos en la introducción, una hipótesis señala que la presencia de un denso infiltrado de linfocitos $\mathrm{T} \mathrm{CD}^{+}$en la base del QA podría tener un efecto en su regresión. Por su parte, otra se apoya en su origen en la vaina radicular externa del folículo piloso, que involuciona de manera natural ${ }^{1}$. El estudio sobre la naturaleza de este tumor podría revelar pistas terapéuticas para otras patologías oncológicas ${ }^{2}$.

La conducta expectante no es la primera elección en el QA solitario. Sin embargo, en los pacientes que rechazan la cirugía o cuando la lesión comienza a involucionar después de la biopsia, como en los casos clínicos comentados, se convierte en una opción posible ${ }^{13}$. Es importante sostener esta decisión en una buena relación médico-paciente, trabajar sobre el desarrollo de pautas de alarma y evaluar su capacidad de cumplir con un seguimiento clínico estricto. Destacamos la buena evolución de ambos pacientes $\mathrm{y}$, además, planteamos la necesidad de nuevos estudios que ahonden en la diferenciación certera con el CEC y en los mecanismos de regresión del QA, necesarios para comprender la evolución natural de esta afección.

8. Browne F, O'Connell M, Merchant W, Potts E, et ál. Spontaneous resolution of a giant keratoacanthoma penetrating through the nose. Clin Exp Dermatol 2011;36:369-371.

9. Ko CJ, McNiff JM, Bosenberg M, Choate KA. Keratoacanthoma: clinical and histopathologic features of regression. J Am Acad Dermatol 2012;67:1008-1012.

10. González Martínez A, Pérez Castro C, Preti C, Corbella MC, et ál. Queratoacantoma. Dermatol Argent 2019;25:1-15.

11. Tran DC, Li S, Henry AS, Wood DJ, et ál. An 18-year retrospective study on the outcomes of keratoacanthomas with different treatment modalities at a single academic center. $\mathrm{Br} J$ Dermatol 2017;177:1749-1751.

12. Ferreira Magalhães $R$, Torres Cruvinel G, Fontes Cintra F, Cintra $\mathrm{ML}$, et ál. Diagnosis and follow-up of keratoacanthoma-like lesions: clinical-histologic study of 43 cases. J Cutan Med Surg 2008;12:163-173.

13. Enei Gahona ML, Machado Filho CAS. Spontaneous involution of keratoacanthoma, iconographic documentation and similarity with volcanoes of nature. An Bras Dermatol 2012;87:335-336. 